\title{
FLOW-INDUCED RELEASE OF ENDOTHELIUM-DERIVED RELAXING FACTOR DURING PULSATILE BYPASS: EXPERIMENTAL STUDY IN THE FETAL LAMB
}

Gérard Champsaur, $\mathrm{MD}^{\mathrm{a}}$

Catherine Vedrinne, $\mathrm{MD}^{\mathrm{b}}$

Stéphane Martinot, $\mathrm{MVD}^{\mathrm{c}}$

François Tronc, $\mathrm{MD}^{\mathrm{a}}$

Jacques Robin, MD ${ }^{\mathbf{a}}$

Jean Ninet, $\mathrm{MD}^{\mathrm{a}}$

Michel Franck, MVD ${ }^{c}$
Objective: This study was initiated to test the hypothesis that fetal hemodynamic changes observed under pulsatile flow bypass might be related to the release of endothelium-derived relaxing factor through oscillating shear stress. Methods: Normothermic bypass was instituted in utero in 21 preterm fetal lambs for a 1-hour period through the right atrium and main pulmonary artery. Ultrasonic flowmeters were positioned around the descending aorta and the umbilical artery. The circuit consisted of an oxygenator and a pump set to either continuous flow $(n=7)$ or pulsatile flow $(n=7)$ and adjusted to maintain a fetal main arterial pressure of $50 \mathrm{~mm}$ Hg. In seven other animals, endothelium-derived relaxing factor was blocked by a continuous infusion of $N^{\omega}$-nitro-L-arginine after 30 minutes of pulsatile flow. Results: During the first 30 minutes of bypass, pump flows were significantly lower in the continuousflow group than in the pulsatile-flow or blocked-flow groups (respectively, $612 \pm 144,907 \pm 153$ and $987 \pm 228 \mathrm{ml} / \mathrm{min}$ ), with similar changes in aortic and umbilical flows. Systemic vascular resistances were significantly lower in the pulsatile-flow and blocked-flow groups than in the continuous-flow group $\left(550 \pm 106\right.$ vs $\left.821 \pm 212 \mathrm{dynes} / \mathrm{sec} / \mathrm{cm}^{-5}\right)$. However, after blockade of endothelium-derived relaxing factor, resistances increased gradually in the blocked-flow group to reach the level of that of the continuous-flow group at the end of bypass $\left(943 \pm 77 \mathrm{vs} 556 \pm 143 \mathrm{dynes} / \mathrm{sec} / \mathrm{cm}^{-5}\right.$ in the pulsatile-flow group). Conclusions: Blockade of endothelium-derived relaxing factor after $\mathbf{3 0}$ minutes of pulsatile flow returns fetal hemodynamics to continuous flow conditions. The specific inhibitor of endothelium-derived relaxing factor used in this experiment suggests that nitric oxide may be released by fetal endothelium during pulsatile bypass. (J Thorac Cardiovasc Surg 1997; 114:738-45)
Endothelium-derived relaxing factor (EDRF) is a Elabile humoral substance released from the vascular endothelium. The substance is a potent relaxant of the vascular smooth muscle. ${ }^{1}$ It stimulates the

From the Departments of Cardiovascular Surgery and Anesthesia and Postoperative Care, ${ }^{\mathrm{b}}$ Hôpital Cardiologique, and the National Veterinary School, ${ }^{\mathrm{C}}$ Lyon, France.

Supported in part by a research contract (JE1949) with Claude Bernard University.

Read at the Seventy-seventh Annual Meeting of The American Association for Thoracic Surgery, Washington, D.C., May 4-7, 1997.

Received for publication May 6, 1997; revisions requested June 25, 1997; revisions received July 21, 1997; accepted for publication July 22, 1997.

Address for reprints: G. Champsaur, MD, Hôpital Cardiologique, 59 Boulevard Pinel, 69003, Lyon, France.

Copyright (C) 1997 by Mosby-Year Book, Inc.

$0022-5223 / 97 \$ 5.00+0 \quad \mathbf{1 2 / 6 / 8 4 9 4 4}$ soluble enzyme guanylate cyclase, which converts guanosine triphosphate into cyclic guanosine monophosphate. The consequent rise in the concentration of cyclic guanosine monophosphate leads to vasodilatation through inhibition of the contractile apparatus of the vascular smooth muscle. ${ }^{2}$ EDRF has been identified as nitric oxide or a closely related compound and is synthesized from its precursor L-arginine through activation of nitric oxide synthase, found in normally functioning endothelial cells. The L-arginine-nitric oxide pathway is competitively inhibited by analogs such as $N^{\omega}$-nitro-L-arginine (N-NA). ${ }^{3,4}$ The release of EDRF, eliciting endothelium-dependent relaxation of vascular smooth muscle, can be triggered by a number of pharmacologic agents, such as acetylcholine $(\mathrm{ACH})$, but also by physical agents such as electrical-field stimulation, visible light, or pulsatile pressure. ${ }^{5}$

In the fetal lamb model, previous experiments 
Table I. Pulse pressure values in the three groups before (baseline) and after 30 and 60 minutes of bypass

\begin{tabular}{crrr}
\hline & \multicolumn{3}{c}{ Bypass } \\
\cline { 2 - 4 } & \multicolumn{1}{c}{$T 1$} & \multicolumn{1}{c}{$T 2$} & \multicolumn{1}{c}{$T 3$} \\
\hline CF & $13.28 \pm 1.37$ & $0.14 \pm 0.1$ & 0 \\
PF & $13 \pm 2.69$ & $10.42 \pm 2.18$ & $10.14 \pm 1.47$ \\
PB & $13.57 \pm 2.03$ & $10 \pm 1.46$ & $9.57 \pm 1.78$ \\
\hline
\end{tabular}

$C F$, Continuous flow; $P F$, pulsatile flow; $P B$, pulsatile blocked flow; $T 1$, baseline, before bypass; $T 2,30$ minutes of bypass; $T 3,60$ minutes of bypass. Values are expressed in millimeters of mercury.

have shown that irreversible hypoxia and fetal death resulting from placental dysfunction observed after regular normothermic steady-flow bypass could be overcome by the use of either vasoactive agents like prostaglandin synthesis inhibitors ${ }^{6}$ or pulsatile flow. ${ }^{7}$ This latter, when compared with continuous flow, was shown to enhance organ perfusion, particularly of the placenta, through a diminution of vascular resistances. $^{\text {? }}$

Therefore this study was undertaken to test the hypothesis that fetal hemodynamic changes observed during pulsatile flow might be related to the release of EDRF through oscillating shear stress, flow changes, and rhythmic stretching of the arterial wall acting as continuous stimuli on endothelial cells, as demonstrated in some isolated organ preparations. 5 Thus the primary end point of the study was to assess the changes in fetal blood gases, blood flows, and vascular resistances during 1 hour of bypass set to continuous flow (CF group), pulsatile flow (PF group), or pulsatile flow blocked by an infusion of N-NA after a 30-minute pump run (PB group). No attempt was made to evaluate either myocardial performance or postbypass fetal survival.

\section{Material and methods}

All animals included in the study received humane care in compliance with the "Guide of the French National Veterinary School" for laboratory animal studies.

Surgical preparation. Twenty-one mixed-breed Grivette ewes between 110 and 140 days' gestation (term is 147 days) and with a mean weight of $55 \pm 6 \mathrm{~kg}$ were fasted for 24 to 48 hours before the operation. The animals were placed in the supine position on an operating table after induction of anesthesia with diazepam $\left(0.25 \mathrm{mg} \cdot \mathrm{kg}^{-1}\right)$ and ketamine $\left(5 \mathrm{mg} \cdot \mathrm{kg}^{-1}\right)$ intravenously administered via the jugular vein. Ewes were endotracheally intubated and then connected to a volume-cycled respirator (MMS 107 ventilator, MMS, Chelles, France) with a 10 cycles/min respiratory rate and a $15 \mathrm{ml} \cdot \mathrm{kg}^{-1}$ tidal volume, so as to keep the arterial oxygen saturation at $99 \%$ and the arterial
Table II. Blood gases in the three groups at the same time intervals as in Table I

\begin{tabular}{|c|c|c|c|c|}
\hline Variable & $\begin{array}{l}\text { Bypass } \\
\text { flow }\end{array}$ & $T 1$ & $T 2$ & $T 3$ \\
\hline \multirow[t]{3}{*}{$\mathrm{pH}$} & $\mathrm{CF}$ & $7.32 \pm 0.04$ & $7.44 \pm 0.06$ & $7.39 \pm 0.07$ \\
\hline & PF & $7.30 \pm 0.08$ & $7.36 \pm 0.05$ & $7.30 \pm$ \\
\hline & PB & $7.31 \pm 0.03$ & $7.32 \pm 0.05$ & $7.34 \pm 0.08$ \\
\hline \multirow[t]{3}{*}{$\mathrm{Po}_{2}(\mathrm{~mm} \mathrm{Hg})$} & $\mathrm{CF}$ & $18.6 \pm 1.54$ & $114.8 \pm 30.62$ & $122.5 \pm 59.81$ \\
\hline & PF & $20.5 \pm 1.31$ & $94.6 \pm 23.5$ & $93 \pm 27$ \\
\hline & PB & $23.6 \pm 3.39$ & $102.4 \pm 22.93$ & $125.1 \pm 33.31$ \\
\hline \multirow[t]{3}{*}{$\mathrm{PCO}_{2}(\mathrm{~mm} \mathrm{Hg})$} & $\mathrm{CF}$ & $32.2 \pm 6.05$ & $19.1 \pm 2.77$ & $22.6 \pm 3.77$ \\
\hline & PF & $40.9 \pm 5.88$ & $26.4 \pm 8.84$ & $24.9 \pm 8.25$ \\
\hline & PB & $41.72 \pm 5.21$ & $27.4 \pm 2.27$ & $23.6 \pm 5.85$ \\
\hline
\end{tabular}

$\mathrm{PO}_{3}$ Oxygen tension; $\mathrm{PCO}_{2}$, carbon dioxide tension. Other abbreviations as in Table I.

carbon dioxide tension within normal limits. Anesthesia was maintained with inhalation of a mixture of $1 \%$ to $1.5 \%$ halothane supplied by a Fluotec vaporizer (Ohmeda [West Yorkshire], Yorkshire, United Kingdom) and 50\% nitrous oxide. Expired gases (oxygen, carbon dioxide, and halothane) were continuously analyzed with a HewlettPackard HP M1015B analyzer (Hewlett-Packard; Bron, France) to adjust volume and percentage of inspired gases for an optimal ventilation. A large-bore intravenous catheter was inserted into the left jugular vein for fluid infusion to maintain adequate uterine perfusion and avoid fetal and maternal hypoglycemia. An arterial line was introduced in the femoral artery through a cutdown for maternal heart rate and blood pressure monitoring, as well as blood gas sampling.

Fetal surgery was carried out according to a previously described technique. ${ }^{7}$ Essentially, after exposure of the uterus through a low midline laparotomy and a small hysterotomy, ketamine $(50 \mathrm{mg})$ was administered intramuscularly into a fetal hind limb. Through a fetal neck incision, catheters were inserted into the jugular vein and the common carotid artery for fetal perfusion, blood pressure monitoring, and blood gas sampling. The umbilical cord was gently mobilized, and a $4 \mathrm{~S}$ to $6 \mathrm{~S}$ ultrasonic flow probe was placed around the umbilical artery (Transonic Systems, Inc., Ithaca, N.Y.) for placental or umbilical blood flow monitoring, special care being taken to avoid any kinking or tension on the cord. After gentle exteriorization avoiding amniotic fluid losses, the fetus was placed on an isolating pad and the temperature was constantly monitored by a rectal probe. A fetal midline sternotomy was then performed, and the pericardium was opened and suspended. Right and left pulmonary arteries were dissected out and encircled with tapes. An ultrasonic flowmeter (8S to $10 \mathrm{~S}$, Transonic) was positioned around the descending aorta, right after the ductus arteriosus. Purse-string sutures of 5-0 Ti-Cron polyester (Davis \& Geck, Bondoufle, France) were placed on the proximal main pulmonary artery and on the right atrial wall. A 300 $\mathrm{U} / \mathrm{kg}$ dose of heparin was administered intravenously to the fetus. A 12F arterial cannula (Bard SA, Trappes, France) was inserted into the proximal main pulmonary artery and a $14 \mathrm{~F}$ venous canula (Dideco SA, Antony, France) was introduced into the right atrium. After con- 


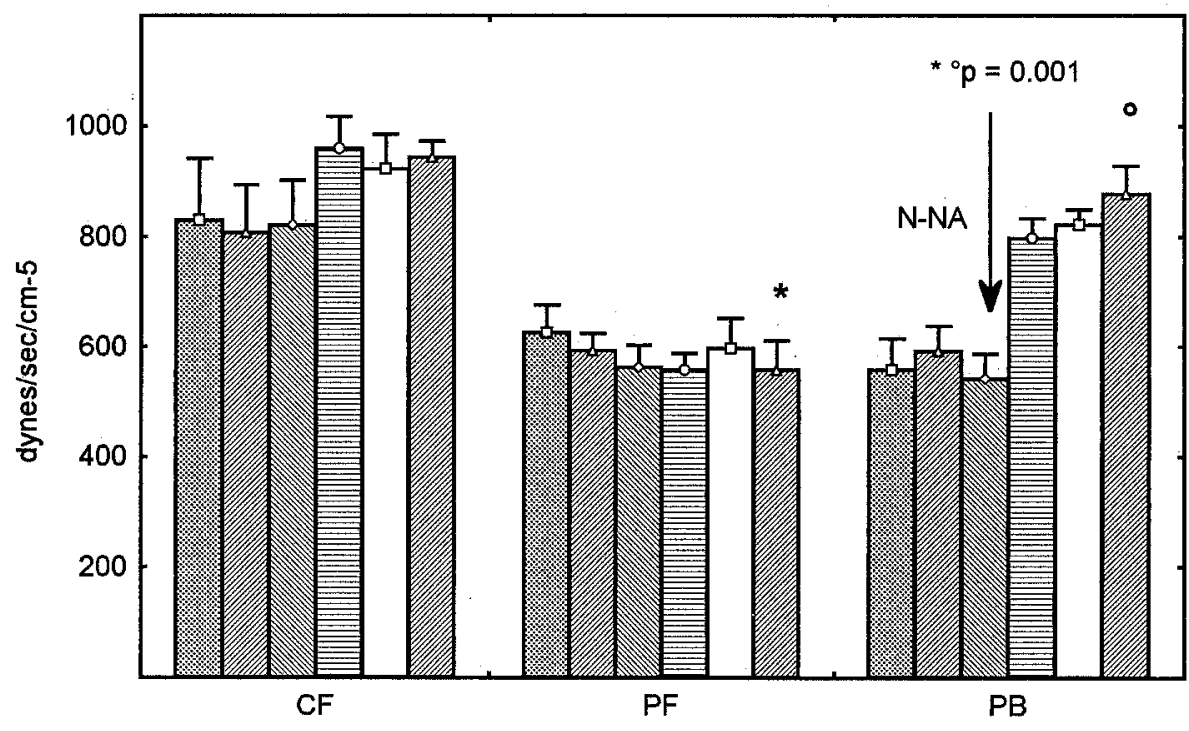

Fig. 1. Systemic vascular resistances in each group: $C F$, Continuous flow; $P F$, pulsatile flow; $P B$, pulsatile blocked flow. The values are depicted in each group every 10 minutes during the bypass time. N-NA ( $N^{\omega}$-nitro-L-arginine) infusion was started at the thirtieth minute of bypass. *Between-group differences at the sixtieth minute of bypass. ${ }^{\circ}$ Within-group differences before and after N-NA infusion.

Table III. Values of pump and aortic and placental blood flows in each group before (T1) and at 30 (T2) and 60 (T3) minutes of bypass

\begin{tabular}{ccccc}
\hline Variable & Group & \multicolumn{1}{c}{$T 1$} & \multicolumn{1}{c}{$T 2$} & $T 3$ \\
\hline Pump flow & CF & & $612 \pm 144^{*}$ & $530 \pm 54$ \\
& PF & & $907 \pm 153$ & $941 \pm 228^{*}$ \\
& PB & & $987 \pm 228^{*}$ & $607 \pm 117$ \\
Aortic flow & CF & $430.71 \pm 82.17$ & $224 \pm 132^{*}$ & $198 \pm 72$ \\
& PF & $478.71 \pm 71.1$ & $458 \pm 213$ & $405 \pm 177^{*}$ \\
& PB & $438.14 \pm 54.42$ & $421 \pm 123$ & $187 \pm 88$ \\
Umbilical flow & CF & $266.14 \pm 47.55$ & $61 \pm 24^{*}$ & $66 \pm 23$ \\
& PF & $232.42 \pm 47.63$ & $181 \pm 71$ & $208 \pm 90^{*}$ \\
& PB & $308.57 \pm 41.11$ & $132 \pm 70$ & $50 \pm 22$ \\
\hline
\end{tabular}

Pump flow in aortic and umbilical flows in are given in milliliters per minute per kilogram.

${ }^{*} p<0.05$ between groups (analysis of variance) at a given time T1, T2, or T3.

nection to the circuit, both right and left pulmonary arteries were occluded by the previously placed tapes to prevent pulmonary arterial overflow, and normothermic bypass was instituted for 60 minutes. After cessation of bypass, the fetus was killed, weighed, and a complete autopsy was performed. Positions of the catheters were checked and all available urine was collected from the bladder by direct puncture, urinary samples being immediately stored at $-20^{\circ} \mathrm{C}$. The placenta was removed from the uterus along with the twin fetus, if any. The hysterotomy and laparotomy were closed in layers. The ewe was then allowed to recover under sedation and antibiotic prophylaxis.
Experimental protocol. The bypass circuit consisted of a bubble oxygenator (Optiflow II, Cobe Laboratories, Inc., Lakewood, Colo.) incorporating a heat exchanger and primed with $700 \mathrm{ml}$ of freshly drawn heparinized adult sheep donor blood diluted with $300 \mathrm{ml}$ of Ringer's lactate solution. The gas flow through the oxygenator was a mixture of $10 \%$ oxygen/90\% nitrogen and was adjusted to maintain fetal oxygen and carbon dioxide tensions within normal limits. Bypass was conducted with a centrifugal pump (Delphin II centrifugal system, Sarns/3M Health Care, Ann Arbor, Mich.) consisting of a $48 \mathrm{ml}$ volume pump head and delivering either a continuous (CF group) or an asynchronous pulsatile flow (PF group) at 60 cycles/min. After the onset of bypass the fetal heart was routinely fibrillated to rule out any contribution to the bypass flow and pulsatility. Pump flows were constantly monitored by an ultrasonic $6 \mathrm{C}$ flow sensor (Transonic) placed around the $1 / 4$-inch arterial line and were adjusted to deliver a fetal mean blood pressure within the physiologic range of 45 to $50 \mathrm{~mm} \mathrm{Hg}$. The animals $(n=21)$ were randomly assigned to one of three groups, according to the type of fetal bypass: continuous flow (CF, $n=7$ ), pulsatile flow ( $\mathrm{PF}, n=7$ ), or blocked pulsatile flow (PB, $n=7)$. In the PB group, so that we could test a potential modification of the vascular endothelium release of vasoactive substances under pulsatile flow conditions, fetuses were perfused with N-NA, a stereospecific EDRF inhibitor (Sigma Chemical Co., St. Quentin Falavier, France). The animals in the PB group received a bolus injection of the diluted N-NA solution $\left(20 \mathrm{mg} \cdot \mathrm{kg}^{-1}\right)$ slowly injected in the fetal jugular vein at the thirtieth minute of bypass, followed by a $20 \mathrm{mg} \cdot \mathrm{kg}^{-1} \cdot \mathrm{hr}^{-1}$ continuous infusion for the next 30 minutes up to the end of bypass. In previous 


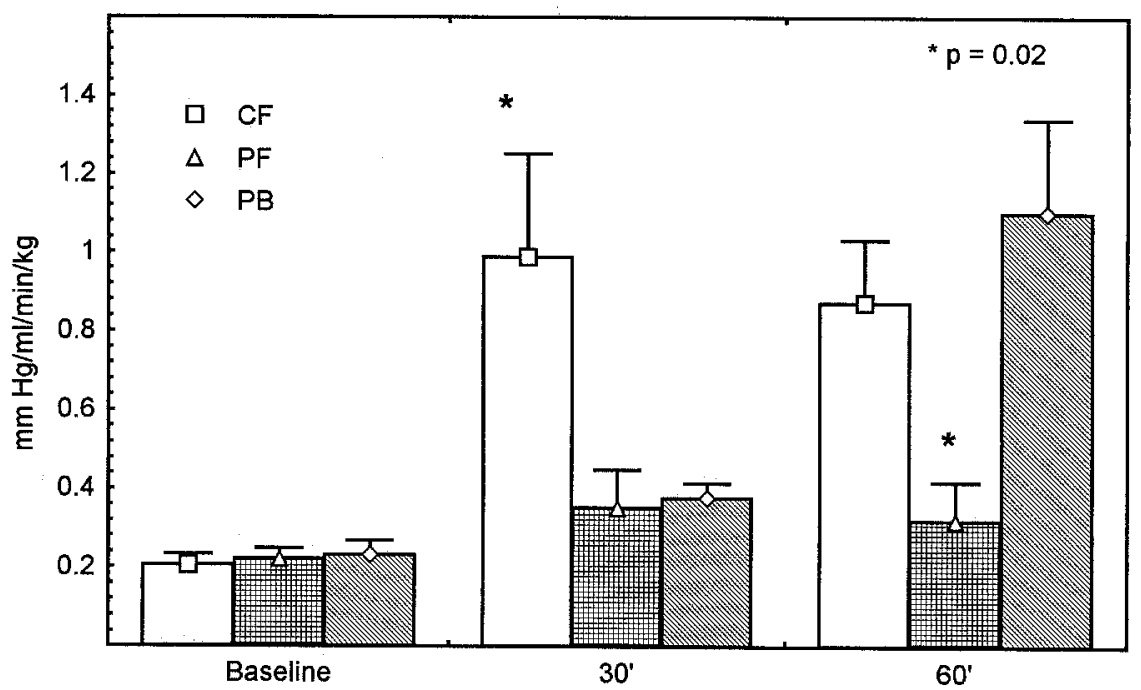

Fig. 2. Placental vascular resistances as calculated before (baseline) and 30 and 60 minutes after the initiation of bypass in each group. Abbreviations as in Fig. 1.

studies, this dose had been shown to block EDRF production. ${ }^{8}$ So that the effectiveness of subsequent EDRF blockade caused by N-NA could be determined, the baseline hemodynamic response to an endothelium-dependent vasodilator was evaluated by injection of $\mathrm{ACH}$, $45 \mu \mathrm{g}$ (Sigma Chemical), into the fetal jugular vein performed at the fortieth minute of bypass. Immediately before each experiment, N-NA, $450 \mathrm{mg}$, was extemporaneously dissolved in a solution of $45 \mathrm{ml}$ of $0.9 \%$ sodium chloride. ACH $10 \mathrm{mg}$ was diluted in $1 \mathrm{~L}$ of sodium chloride, $1 \mathrm{ml}$ representing $10 \mu \mathrm{g}$.

Data acquisition. Fetal and maternal hemodynamic parameters were measured and continuously monitored with Baxter transducers (Uniflow pressure set, Baxter Healthcare Corp., Bentley Laboratories Europe) and multichannel recorders (Kone Corporation Instruments Division, Espoo, Finland). All flows were measured on Transonic T206 flowmeters. Blood gases sampled from maternal femoral and fetal carotid arteries were immediately analyzed (arterial oxygen and carbon dioxide tensions and $\mathrm{pH}$ ) on a Radiometer ABL 330 gas analyzer (Radiometer A/S, Copenhagen, Denmark). Hemoglobin concentration was measured on a hemoglobin photometer (HemoCue, Ängelholm, Sweden).

Data were collected after anesthesia induction, 10 minutes before the onset of bypass, and every 10 minutes thereafter until 10 minutes after the termination of the 60 -minute bypass. Fetal urinary excretion of nitric oxide metabolites (nitrites and nitrates) was measured in the three groups at the end of the procedure, the concentration being measured after dilution in distilled water, and incubation with nitrate reductase and flavine adenosine.

Data analysis. Before the onset of bypass, total cardiac output was not measured because fetal anatomy made placement of a flow probe around the distal aorta, above the ductus, almost impossible without compromising the hemodynamic stability of the animal. Once bypass was begun, flow delivered by the pump in the setting of this preparation with a fibrillating heart and excluded pulmonary circulation could be considered as the cardiac output. Systemic and placental vascular resistances were calculated with the use of standard formulas. Data were stored on a spreadsheet database and were analyzed with CSS Statistica statistical package (Statsoft Inc., Tulsa, Okla.). Values were expressed as mean \pm standard error of the mean. Between-group differences were compared with one-way analysis of variance and repeated-measures twoway analysis of variance. Within-group differences were analyzed with $t$ tests for dependent samples. Nonparametric tests were used when appropriate. Statistical significance was established at the $5 \%$ level.

\section{Results}

Hemoglobin values did not differ in any group before bypass (mean $11.2 \pm 4.1 \mathrm{gm} / \mathrm{dl}$ ) or after 60 minutes, at which time a nonsignificant drop was similar in each group (mean $8.1 \pm 4.1 \mathrm{gm} / \mathrm{dl}$ ). In the $\mathrm{CF}$ group, the pulse pressure disappeared at initiation of bypass because the heart was fibrillating in every group. In both the PF and PB groups, the pulse pressure was not significantly different once bypass was begun (Table I). However, the heart rate was slower, fixed at $60 \mathrm{cycles} / \mathrm{min}$, according to the built-in specifications of the device.

Oximetry. Blood gas data were similar between groups from baseline values until the onset of bypass. Once bypass was begun, there was a trend toward a relative hyperoxia although the oxygenator 


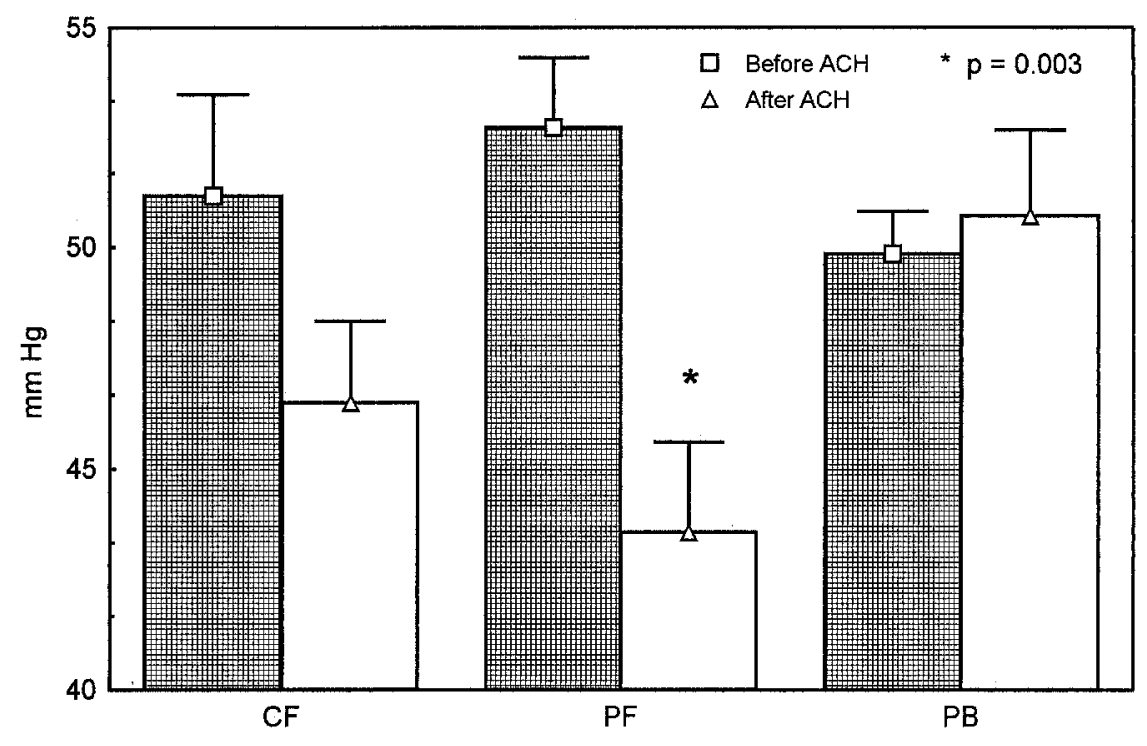

Fig. 3. Changes in the mean arterial blood pressure of fetuses in each group following a bolus injection of acetylcholine $(A C H)$. Abbreviations as in Fig. 1.

was flushed most times with room air, and there were no significant between-group differences at any time during the bypass, whatever the type of flow (Table II).

Hemodynamics. No significant differences in either aortic or umbilical flows were noted among the three groups before bypass (Table III). After 30 minutes of bypass (T2), pump flow in the CF group was significantly lower than in either the PF or PB groups, which by definition did not differ (Table III). The same trend was followed by aortic flow and umbilical flow, which were significantly lower in the CF group. At 60 minutes of bypass, all flows were significantly lower in the $\mathrm{CF}$ than in the $\mathrm{PF}$ group. At this point in the PB group, however, where animals had been submitted to pulsatile flow for 30 minutes with subsequent EDRF blockade by N-NA, all flows decreased to values not different from those of the $\mathrm{CF}$ group, but significantly different from those of the PF group. Flows within the PB group also differed significantly at 30 and 60 minutes of bypass (Table III). Systemic vascular resistances were significantly lower in groups $\mathrm{PF}$ and $\mathrm{PB}$ than in group CF (perfused with continuous flow) (Table III). After EDRF blockade performed in group PB at 30 minutes of bypass, systemic vascular resistances increased gradually to reach the level of those of group CF at the termination of bypass (Fig. 1). Placental vascular resistances followed a similar evolution between and within groups, being not different between $\mathrm{CF}$ and $\mathrm{PB}$ groups at the end of the 60-minute bypass, whereas placental vascular resistances in the $\mathrm{PB}$ group were not different from those of the PF group until EDRF blockade (Fig. 2). $\mathrm{ACH}$ bolus injection at the fortieth minute of bypass (after a 10-minute duration of EDRF blockade) was followed by an immediate and transient drop in blood pressure in both the CF and PF groups, whereas the blood pressure in the $\mathrm{PB}$ group remained unchanged (Fig. 3). Finally, the level of urinary nitrates was lower, although not significantly so, in the CF group $(450.57 \pm 110.36 \mu \mathrm{mol} / \mathrm{L})$ than in either the PF group $(546.28 \pm 53.76 \mu \mathrm{mol} / \mathrm{L})$ or the PB group $(570.85 \pm 85.51 \mu \mathrm{mol} / \mathrm{L})$.

\section{Discussion}

In the era of early prenatal echographic diagnosis of most congenital defects, along with clinical fetal surgery performed for noncardiac defects, ${ }^{10}$ the search for an optimal technique of fetal bypass still goes on. In this direction, we have investigated the potential benefits of adding a pulsatile flow to fetal perfusion. We had shown in a preliminary work ${ }^{7}$ that pulsatility improves hemodynamics during fetal bypass through a significant decrease of systemic and placental vascular resistances. The present study was then undertaken after the observation that modifications in flows, and particularly pulsatile flows, are known triggers of EDRF release on isolated arterial segments. ${ }^{3,5}$ 
When applied to clinical cardiac surgery, pulsatile flow remains a highly controversial subject, ${ }^{11}$ partly because most pulsatile devices used in this setting are unable to deliver a proper pulsatile flow. ${ }^{12}$ Regarding our own preparation, one of the main criticisms is related to the specifications of the pump, which on the pulsatile mode has a fixed rate of $60 \mathrm{beats} / \mathrm{min}$, much slower than the physiologic preterm fetal heart rate. ${ }^{8}$ However, the pulse pressure during bypass was not significantly different from the prebypass one.

Other investigators have extensively explored other ways of improving the tolerance of fetal bypass, including the addition of vasodilators, ${ }^{6,13}$ steroids, ${ }^{14}$ the prevention of fetal stress, ${ }^{15}$ or the use of less invasive perfusion techniques, ${ }^{16}$ but always on a shorter bypass run (30 minutes). We have concentrated instead on triggering the release of endothelial autacoids by mechanical means such as flow changes with a 60-minute bypass time. The use of an oxygenator then becomes mandatory to maintain fetal blood gases at a constant level, thus ruling out hemodynamic biases, and to keep the animal temperature constant over time. In the current study, normothermia was part of the fetal stress management, along with fetal anesthesia and delicate manipulation avoiding amniotic fluid losses. Conversely, the oxygenator brings up other related issues like exposure to increased blood-contacting surfaces and priming volume with adult sheep blood. These are widely known factors of placental dysfunction ${ }^{16}$ and of endothelial dysfunction that we were not willing to eliminate because they are part of clinical cardiopulmonary bypass.

The current study confirms the benefits of pulsatile flow in this specific preparation for up to 1 hour of bypass to maintain systemic and placental vascular resistances at an acceptable level that is also significantly lower than that observed during continuous flow. EDRF blockade as it is achieved through N-NA infusion seems then to simulate the endothelial dysfunction resulting from the continuous flow perfusion, with a return to similar flow values after 30 minutes of EDRF release inhibition. The endothelium-dependent ACH action is also confirmed, the animals in the $\mathrm{PB}$ group remaining insensitive to the drug. In the $\mathrm{CF}$ group, however, the $\mathrm{ACH}$ induced pressure drop was constantly observed, although the pressure change was not significant as compared with the one observed in the PB group. This may suggest that the endothelial dysfunction observed during continuous flow was less severe than that generated by EDRF blockade. $\mathrm{ACH}-$ induced vasodilation observed during fetal bypass suggests that nitric oxide synthase is present in fetal endothelium, as pointed out by other investigators. ${ }^{17,}, 18$

It remains unclear why the urinary nitrate levels did not differ significantly between the pulsatile (PF and $\mathrm{PB}$ ) and nonpulsatile (CF) groups. First, fetal diuresis was difficult to quantify, the bladder not being empty at the beginning of the experiment and the whole volume of urine being collected at the end of the procedure. Second, in the absence of sequential urinary sample collection during the bypass period, it was impossible to discriminate in the $\mathrm{PB}$ group which concentration was due to either pulsatile flow or blocked pulsatile flow.

Thus pulsatile perfusion may act as a donor of EDRF. The explanation for EDRF release during pulsatile flow usually invoked in experiments on isolated arterial segments is that of rhythmic stimulation of endothelial cells through oscillating changes in vessel wall shear stress. 2,3,5 This may stimulate a renewed interest in pulsatile perfusion for patients with impaired endothelial function, particularly in three clinical situations. One is the elderly patient in whom the aging or regenerated endothelium $^{3}$ may benefit from an EDRF donor during perfusion. The same suggestion is potentially applicable to atherosclerosis-damaged arterial wall. The third situation is that of jeopardized myocardium with severe impairment of endothelial function for the reversal of which, among other adjuncts, L-arginine supplementation has been advocated. ${ }^{19}$ Pulsatile flow reperfusion would theoretically bring the same advantages in this situation.

In summary, when pulsatile flow during fetal bypass is subjected to a competitive EDRF inhibitor, systemic and placental vascular resistances return to values not different from those observed in the same conditions during continuous flow. This suggests that pulsatile bypass may stimulate nitric oxide release from endothelial cells.

We acknowledge the expert technical assistance of M. T. Poirel, ENV, Lyon, France.

\section{REFERENCES}

1. Furchgott RF, Zawadzki J. The obligatory role of endothelial cells in the relaxation of arterial smooth muscle by acetylcholine. Nature 1980;288:373-6. 
2. Vane JR, Anggard EE, Botting RM. Regulatory functions of the vascular endothelium. N Engl J Med 1990;323:27-36.

3. Vanhoutte PM, Boulanger CM, Monbouli JV. Endotheliumderived relaxing factors and converting enzyme inhibition. Am J Cardiol 1995;76:3E-12E.

4. Ishii K, Chang B, Kerwin JF, Huang ZJ, Murad F. $N^{\omega}$-NitroL-arginine: a potent inhibitor of endothelium-derived relaxing factor formation. Eur J Pharmacol 1990;176:219-23.

5. Pohl U, Busse R, Kuon E, Bassenge E. Pulsatile perfusion stimulates the release of endothelial autacoids. J Appl Cardiol 1986; 1:215-35.

6. Sabik JF, Assad RS, Hanley FL. Prostaglandins synthesis inhibition prevents placental dysfunction after fetal cardiac bypass. J Thorac Cardiovasc Surg 1992;103:733-42.

7. Champsaur GL, Parisot P, Martinot S, Ninet J, Robin J, Ovize $\mathrm{M}$, et al. Pulsatility improves hemodynamics during fetal bypass: experimental comparative study of pulsatile versus steady flow. Circulation 1994;90(Suppl):II47-50.

8. Fineman JR, Heymann MA, Soifer SJ. $N^{\omega}$-Nitro-L-arginine attenuates endothelium-dependent pulmonary vasodilatation in lambs. Am J Physiol 1991;29:H1299-306.

9. Conrad KP, Vill M, Kruszyna H, Kruszyna R, Rochelle LG, Smith RP, et al. Identification of increased NO biosynthesis during pregnancy in rats. FASEB J 1993;7:566-71.

10. Harrison MR. Fetal surgery. Am J Obstet Gynecol 1996;174: 1256-64.

11. Hickey PR, Buckley MJ, Philbin DM. Pulsatile and nonpulsatile cardiopulmonary bypass: review of a counterproductive controversy. Ann Thorac Surg 1983;36:720-37.

12. Runge TM, Trinkle JK. Does flow character of cardiopulmonary bypass make a difference? J Thorac Cardiovasc Surg 1994;107:642-4.

13. Bradley SM, Hanley FL, Duncan BW, Jennings RW, Jester JA, Harrison MR, et al. Fetal cardiac bypass alters regional blood flows, arterial blood gases, and hemodynamics in sheep. Am J Physiol 1992;263:H919-28.

14. Sabik JF, Heinemann MK, Assad RS, Hanley FL. High-dose steroids prevent placental dysfunction after fetal cardiac bypass. J Thorac Cardiovasc Surg 1994;107:116-25.

15. Fenton KN, Heinemann MK, Hickey PR, Klautz RJM, Liddicoat JR, Hanley FL. Inhibition of the fetal stress response improves cardiac output and gas exchange after fetal cardiac bypass. J Thorac Cardiovasc Surg 1994;107: 1416-22.

16. Reddy VM, Liddicoat JR, Klein JR, McElhinney DB, Wampler RK, Hanley FL. Fetal cardiac bypass using an in-line axial flow pump to minimize extracorporeal surface and avoid priming volume. Ann Thorac Surg 1996;62:393400.

17. Fox JJ, Ziegler JW, Ivy DD, Halbower AC, Kinsella JP, Abman SH. Role of nitric oxide and cGMP system in regulation of ductus arteriosus tone in ovine fetus. Am $\mathbf{J}$ Physiol 1996;271:H2638-45.

18. Thompson LP, Weiner CP. Acetylcholine relaxation of renal artery and nitric oxide synthase activity of renal cortex increase with fetal and postnatal age. Pediatr Res 1996;40: 192-7.

19. Sato H, Zhao Z-Q, McGee DS, Williams MW, Hammon JW Jr, Vinten-Johansen J. Supplemental L-arginine during cardioplegic arrest and reperfusion avoids regional postischemic injury. J Thorac Cardiovasc Surg 1995;110:302-14.

\section{Discussion}

Dr. Robert C. Robbins (Stanford, Calif.). I have just a few questions. You mentioned the stress response. What anesthetic agents did you use?

Second, we have also used an oxygenator system and a total extracorporeal system for fetal bypass in lambs. Did you use hyperoxygenation or did you use low levels of oxygenation? We have been concerned that using high levels of oxygenation might affect the ductus.

Finally, you mentioned that you obtained blood gases. I would like to know what happens after bypass in these animals? In our experience the flows and blood gases are fine during bypass, but then within an hour or two after, the animal becomes acidotic, especially when we use hyperoxygenation.

Dr. Champsaur. Thank you for your nice remarks. We used ketamine in the fetuses, intramuscularly, as an anesthetic agent, and we did try to keep the level of oxygenation as close as possible to the physiologic level. Nevertheless, after the end of 1 hour of bypass, there was some trend toward hyperoxia.

Finally, to address the question regarding blood gases, the study was not aimed at fetal survival, so we were not interested in the late outcome of the fetus after bypass. The animals were routinely killed at the end of the procedure.

Mr. Magdi Yacoub (London, United Kingdom). I have three very quick questions. Why did you select a fetal model? Do you think there is difference between fetal and adult models?

Second, have you quantified the amount of pulsatility? Do you think that matters, whether there is a minimum amount of pulsatility required or there is a dose-response relationship?

Finally, what do you think is the relationship between the capacity of the endothelium to respond to pharmacologic or mechanical stimuli? Are these two completely separate things, or are they linked?

Dr. Champsaur: Thank you, Mr. Yacoub, for your remarks. Why the fetal model? The reason is that we have used that model for a couple of years now and we are more familiar with it than with any other model. We also think that this is a very highly sensitive model for the study of the circulation as compared with adult animals.

Regarding the amount of pulsatility, the pulse pressure remained fairly stable during the whole procedure in the PF group, with a pulse pressure of about 30 to $35 \mathrm{~mm} \mathrm{Hg}$. The hearts were routinely fibrillated to rule out any contribution of the native heart to either flow or pulsatility.

Dr. John H. Kennedy (Cambridge, United Kingdom). I have only one simple question. In your abstract you refer to measurements of shear stress. How was shear stress measured?

Dr. Champsaur. There was no direct measurement of the shear stress in this study, and I don't think there was any reference to shear stress measurement in the abstract. We hypothesized that pulsatile flow would act through a shear stress modification during pulsatile flow, but there was no direct measurement of that particular variable. 
Dr. James Frederiksen (Chicago, Ill.). You said that you kept the arterial pressure at $50 \mathrm{~mm} \mathrm{Hg}$. Can you increase the continuous flow to $900 \mathrm{ml} / \mathrm{min}$ if you increase the mean arterial pressure?

Dr. Champsaur. Yes, we certainly could do so. The main end point was to keep the blood pressure level within physiologic limits, which in this particular case is around $50 \mathrm{~mm} \mathrm{Hg}$. By increasing the flows in the continuous-flow preparation, we were able to increase also the blood pressure very rapidly, but to a really high hypertensive level that was unsafe to keep anyway. Again, this was not the aim of the study.

Dr. Edward D. Verrier (Seattle, Wash.). My final question has to do with the relative importance of the prostaglandin system versus nitric oxide. Work that Frank Hanley and we have done previously at the University of California at San Francisco showed that the placenta is an extraordinarily rich circulation with prostaglandins. Indomethacin blocks all of these responses. Can you put into context what you think is the relative importance of prostaglandin to EDRF in terms of regulation of the fetal circulation or the placental circulation based on this work?

Dr. Champsaur. Dr. Verrier, we are very well aware of your previous work on the fetal bypass and circulation. What I know is that prostaglandin inhibitors, as they have been used by Frank Hanley and your group in the past, are endothelium-independent factors, whereas the pulsatile flow indirectly might be an endothelium-dependent factor through EDRF release and that may be the main difference between the two studies.

\section{Bound volumes available to subscribers}

Bound volumes of The Journal of Thoracic and Cardiovascular Surgery are available to subscribers (only) for the 1997 issues from the Publisher, at a cost of $\$ 110.50$ for domestic, $\$ 139.64$ for Canadian, and $\$ 130.50$ for international subscribers for Vol. 113 (January-June) and Vol. 114 (July-December). Shipping charges are included. Each bound volume contains a subject and author index and all advertising is removed. Copies are shipped within 60 days after publication of the last issue of the volume. The binding is durable buckram with the Journal name, volume number, and year stamped in gold on the spine. Payment must accompany all orders. Contact Mosby-Year Book, Inc., Subscription Services, 11830 Westline Industrial Drive, St. Louis, Missouri 63146-3318, USA; phone $800-453-4351$ or $314-453-4351$.

Subscriptions must be in force to qualify. Bound volumes are not available in place of a regular Journal subscription. 